\title{
Web services to link interlibrary software with OCLC WorldShare
}

\author{
Josep-Manuel Rodríguez-Gairín and Marta Somoza-Fernández \\ Department of Library and Information Science, University of Barcelona, \\ Barcelona, Spain
}

\begin{abstract}
Purpose - This article describes the use of web services to interconnect the GTBib interlibrary loan program with the OCLC WorldShare platform.

Design/methodology/approach - We describe the current problem of duplication of procedures in libraries that have added their collections to the OCLC WorldCat catalogue in recent years and are therefore more likely to receive interlibrary loan requests through the WorldShare Platform.

Findings - A solution that uses web services to insert and retrieve requests between the two systems is presented. Autonomous agents periodically check the status of the requests and keep them updated and synchronized. These agents also inform the library staff of any variation or inconsistency that is detected.

Practical Implications - This technology reduces process management time by making it unnecessary to introduce the request data in both systems. Agents are used to check the consistency of statuses between the two systems, thus avoiding errors and omissions and improving the efficiency of the whole interlibrary loan process.

Originality/value - This paper describes in detail the technical aspects of the solution as a reference for the development of future applications.
\end{abstract}

Keywords Interlibrary loan, Interoperability, Spain, Web services, SOAP, OCLC WorldShare, GTBib, autonomous agents.

\section{Paper type Technical paper}

\section{Introduction}

The increase in global scholarly communication involves not only idea sharing, co-authorship, and conference participation, but also interlibrary cooperation. Prominent among international library activity is interlibrary loan (ILL). Because the market for library software is often national or regional, success in international ILL faces a potential obstacle when different software systems are in place. The concept of web services offers a solution.

A web service is a software technology that facilitates the exchange of data between two applications using a set of protocols and open standards that allow them to interoperate. Concepts such as web services description language (WSDL), extensible markup language (XML), simple object access protocol (SOAP) and representational state transfer (REST) are the terminology associated with these services.

In a web service, one of the applications acts as a service provider and the other acts as a service requester. The communication takes place through the World Wide Web using HTTP and the data are structured using XML. The exchange of messages is encapsulated using SOAP. Since the two applications may have been developed by different companies, the whole process must be highly structured. In the first step, the service provider shows the user the language and a list of the operations or data that it can offer: this is done in WSDL. As this computer terminology can be particularly challenging for readers not specialized in the more technical aspects, a practical example may better illustrate these concepts.

One of the first companies to develop these technologies to provide information about its products was Amazon. When we use a browser to view a search result, we can easily identify the title, bibliographic data,

This article is (c) Emerald Group Publishing and permission has been granted for this version to appear here http://diposit.ub.edu . Emerald does not grant permission for this article to be further copied/distributed or hosted elsewhere without the express permission from Emerald Group Publishing Limited 
price and rating of the books. However, if the service requester is a computer application that must later process these data, the data must be structured (XML), with prior information on what can be obtained and the content of each field (WSDL). The application can then process these data, combine them with others or discriminate them (e.g. processing only those that do not exceed a given cost) to provide the user with an added value on the original data.
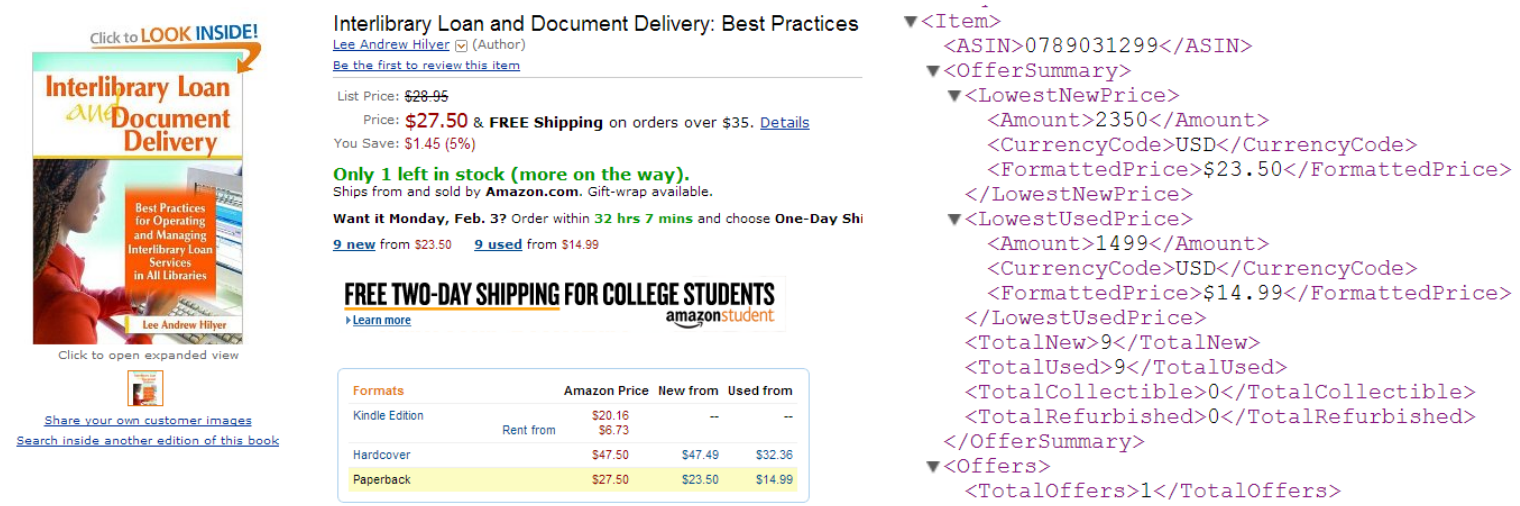

Figure 1 Amazon results: Human-eyes display versus machine-readable display

As an example we can mention the Getting It System Toolkit (GIST), an application developed by the State University of New York that is integrated with the OCLC's ILLiad interlibrary loan system. GIST provides different application programming interfaces (APIs) to interact with different services. For example, through the Amazon API, when a patron submits a request, the system automatically retrieves, from among other data, the price, the ratings and the recommendations, thus helping the patron to decide whether to purchase the book (Pitcher et al., 2010)

The use of web-based services in libraries has increased markedly in recent decades (Zarei and Abazari, 2011). However, we should not confuse providing library services through the Internet with the specific computing concept of a web service described herein.

Web services have a great potential (Wusteman, 2006) and are being used in many library processes, including cataloging, interacting with controlled languages and reference services (Vizine-Goetz et al., 2006), accessing bibliographic databases such as Pubmed (Eberle, 2000), and collaborative tasks such as sharing activities and events (Henzel et al., 2006). In all these processes web services facilitate the search tasks and reduce the time used. The fact that they are based on standards allows them to be used in conjunction with the primary program of the process, which in many cases is proprietary (the OCLC catalog, the EBSCO databases, the Millenium cataloging module, etc.). Web services have proven to be highly effective when applied to mobile technologies, smartphones and digital tablets (Schall et al., 2006), especially when associated with the use of software agents (Ishikawa et al., 2005; Rykowski, 2007).

OCLC has APIs with a great variety of web services. Some of these, such as the ones shown in Table 1, are particularly interesting in ILL for locating documents (OpenURL Gateway), filling in bibliographic data (XISBN, XISSN), obtaining information on suppliers (ILL polices Directory), and other processes that are directly related to the transaction.

\begin{tabular}{|c|c|c|}
\hline Article Exch & & A write web service for cloud-based document delivery. Provides \\
\hline Interlibrary & Loan & A read only web service that allows a developer to send a query about an \\
\hline
\end{tabular}

This article is (c) Emerald Group Publishing and permission has been granted for this version to appear here http://diposit.ub.edu . Emerald does not grant permission for this article to be further copied/distributed or hosted elsewhere without the express permission from Emerald Group Publishing Limited 


\begin{tabular}{|c|c|}
\hline Policies Directory & $\begin{array}{l}\text { OCLC member library using their OCLC Symbol or Registry ID and in } \\
\text { return receive ILL policies information about that institution. }\end{array}$ \\
\hline OpenURL Gateway & $\begin{array}{l}\text { An OpenURL-resolving Web service that redirects Web-based applications } \\
\text { to provide their end-users direct access to full-text articles and other online } \\
\text { resources available from libraries. }\end{array}$ \\
\hline WMS NCIP Service & $\begin{array}{l}\text { A Web service to handle common library user-facing functions based on } \\
\text { the industry standard NCIP functionality }\end{array}$ \\
\hline xISBN & $\begin{array}{l}\text { Submit an ISBN to this service, and it returns a list of related ISBNs and } \\
\text { selected metadata. }\end{array}$ \\
\hline xISSN & $\begin{array}{l}\text { Submit an OCLC Number, LCCN or OCLC work ID to this service and } \\
\text { get back a list of associated OCLC numbers and brief metadata. }\end{array}$ \\
\hline
\end{tabular}

Table 1: Some useful web services that can be used in the ILL workflow. Source http://oclc.org/developer/webservices

\section{Standards and protocols}

Interlibrary loan (ILL) transactions are regulated by the standards ISO 10160 (Loan Application Service Definition) (International Organization for Standardization, 1997a) and ISO 10161 (Interlibrary Loan Application Protocol Specification) (International Organization for Standardization, 1997b). These standards were established nearly 20 years ago and over the years have not been free of controversy. Subsequent revisions have received criticism from several member countries of the technical committee. They have also come under fire from companies specializing in library technology, either because they failed to provide them with a business opportunity or because they involved a high cost of implementation for the improvements offered (Jackson, 2005). In fact, the third revision failed to include the use of SOAP or XML, leading authors such as Jackson to predict an uncertain future for these regulations. This uncertainty is illustrated by the fact that neither of the standards has been revised in recent years.

The NISO circulation interchange protocol (NCIP Z39.83) (National Information Standards Organization, 2012) has made important progress in this area because it can be defined as an XML-based standard (Needleman et al., 2001) and the leading developers of library software participated in creation. This protocol applies to both local transactions in the catalog of libraries and the circulation of documents between members of library consortia, and of course it extends to ILL in general. Unlike in previous standards, the individuals and organizations involved in its development have been highly active, with frequent virtual and face-to-face meetings resulting in the publication of version 2.02 in 2012.

In addition to all these technical standards, it is important to note that ILL is governed by different guidelines, such as the Interlibrary Loan Code for the United States (Interlibrary Loan Committee, 2008) and International Lending and Document Delivery: Principles and Guidelines for Procedure (International Federation of Library Associations and Institutions, 2001). For international loan we must also consider International Resource Sharing and Document Delivery: Principles and Guidelines for Procedure (International Federation of Library Associations and Institutions, 2009). National agencies have also developed local protocols, such as the Procedural Manual for Interlibrary Loan drawn up by the Spanish Network of University Libraries (REBIUN) (Grupo de trabajo de préstamo Interbibliotecario de REBIUN, 2013).

The introduction of electronic documents that can be purchased on demand or delivered directly to the end user has forced continuous revisions of these recommendations. However, their interpretation is not always easy, especially when the interests of publishers conflict with those of libraries and users. An example of this is the controversy created between the International Association of Scientific, Technical \& Medical

This article is (c) Emerald Group Publishing and permission has been granted for this version to appear here http://diposit.ub.edu . Emerald does not grant permission for this article to be further copied/distributed or hosted elsewhere without the express permission from Emerald Group Publishing Limited 
Publishers (STM) and the International Coalition of Library Consortia (ICOLC) following a document published by the STM (International Association of Scientific Technical \& Medical Publishers, 2011) and the response of the ICOLC (International Coalition of Library Consortia, 2011). This controversy showed the discrepancy of the two institutions in areas such as digital document delivery directly to end-users and the applicable copyright laws.

\section{The scenario}

Since 1992 interlibrary loan (ILL) has been managed in most Spanish universities with the program GTBibSOD (Rodríguez-Gairín, 2012). Unlike other library networks, such as Nilde (Mangiaracina et al., 2008) and OCLC, which use a centralized management system associated with the union catalogue, GTBib was designed as a decentralized system in which each university has the application installed on its servers. As communication between libraries is essential in this service, the capabilities for doing this were enhanced either through email or through web services. GTBib generates links using the openURL standard, which allows it to insert the bibliographic data of the requests into external systems such as SUBITO and NILDE. It uses SOAP web services to automatically insert requests between GTBib systems and send electronic documents and messages, and to synchronize the request status in both systems.

Spanish university libraries have traditionally had few relations with the OCLC regarding ILL. The physical distance between them increases the time and cost, so it has normally been preferred to use European libraries.

In terms of ILL requests, in the 1990s the leading international provider of documents was the British Library. Subsequently the relations were extended to European consortia such as SUBITO in Germany, INIST in France, and NILDE in Italy. In certain specialties, such as history, philology and the humanities in general, relations were established with specific French and Italian libraries. In the area of medicine there were some cases of relations with American libraries, such as that of the Josep Laporte Foundation Library (Universitat Autònoma de Barcelona), which is accredited as a DocLine centre of the National Library of Medicine.

At the supply level the situation has been similar. American libraries have only used Spanish ones for very specific document types such as doctoral theses and very specific topics related to history or philology, and in many cases the relationship has been with National Library of Spain.

This situation has been gradually changing in recent years. The electronic format significantly mitigates the problems associated with delivering documents and therefore eliminates the time and cost of sending them by post. However, the most important factor may have been the increased visibility created by the gradual inclusion of library collections in the OCLC Union Catalogue and the acquisition of WorldCat Local by consortia such as BUCLE (Murphy, 2011).

\section{The problem}

GTBib and WorldShare are both ILL management systems that cover all the processes involved. Both create a record for each request and maintain its status in every step of the process. When the record is introduced into the system, it acquires "pending" status in WorldShare or "status 1" in GTBib. When the request has been processed it has "in process" status in WorldShare or "status 2" in GTBib, and so on.

Libraries that have incorporated their collections in WorldCat or are using the OCLC ILL modules have to duplicate the task of entering requests and ensuring that their status is updated. Often, after entering a request

This article is (c) Emerald Group Publishing and permission has been granted for this version to appear here http://diposit.ub.edu . Emerald does not grant permission for this article to be further copied/distributed or hosted elsewhere without the express permission from Emerald Group Publishing Limited 
in GTBib and receiving a positive response in the program, ILL staff forget to connect to the OCLC interface to record it, especially if they do not perform this task regularly. Similarly, if the volume of requests received is small, the library does not connect daily to the OCLC interface to check whether any requests have received. In fact, this task may be performed so infrequently that when the requests are checked the response time set by the requester has been exceeded.

\section{The proposed solution}

As stated above, GTBib has the ability to consume web services and also act as a provider of such services. The new version of OCLC WorldShare Interlibrary Loan service (Duke, 2013) offers a new range of possibilities for ILL by facilitating interaction with other programs through web services. The WorldShare Platform facilitates interoperability with other systems and can act as a web service provider. The services currently offered are included in version 1.6 of OCLC WSDL and include searching for, creating and updating requests.

The proposed solution involves developing a client that interacts with these services as follows:

- $\quad$ Automatically filling the request in the WorldShare platform with bibliographic data extracted from the GTBib record and the constant data from the library directory. This will call the createRequest service.

- Obtaining a list of active requests in the OCLC system (calling the searchRequestsByCategory and retrieveResults services), whether pending management (status pending), being processed (status in_process), supplied (status shipped) or unfilled (status unfilled).

- $\quad$ Obtaining information on the status and details of each request (calling the retrieveRequest service).

- Changing the status of the request automatically (calling the updateRequest service).

Technically, the client is developed using PHP's NuSOAP library adapted to meet OCLC's requirement of sending the user-agent metadata of the http header with a previously agreed specific name. If this is not done, the OCLC server always returns a 404 error. A second technical aspect to consider is that the web client must manage the sessions because the OCLC service sends a cookie identified with the attribute JSESSIONID

Set-Cookie: JSESSIONID=49EBBB19A1B2F8D10EE075F6F14CB8C9

and waits to receive these data in the HTTP header in the following connection

Cookie: JSESSIONID = 49EBBB19A1B2F8D10EE075F6F14CB8C9

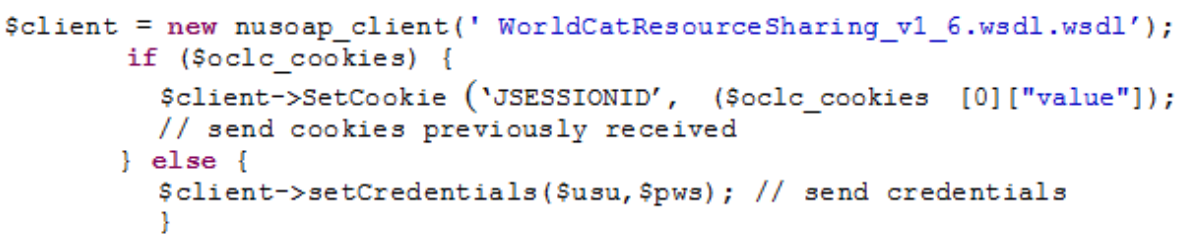

Figure 2. Sample code fragment for authentication or sending the cookies received

This article is (c) Emerald Group Publishing and permission has been granted for this version to appear here http://diposit.ub.edu . Emerald does not grant permission for this article to be further copied/distributed or hosted elsewhere without the express permission from Emerald Group Publishing Limited 
This client operates automatically when a change of state occurs in GTBib. For example, when a positive response to a request is given in GTBib, the status in WorldShare is automatically updated to YES. The table 2 lists these actions.

\begin{tabular}{lll}
\hline Action in the GTBib system & $\begin{array}{l}\text { Modification of the status in } \\
\text { WorldShare }\end{array}$ & Resulting status \\
\hline A request enters & IN_PROCESS & IN_PROCESS \\
Give positive response & YES & SHIPPED \\
Give negative response & NO & UNFILLED \\
Give conditional response & CONDITIONAL & CONDITIONAL_PENDING \\
\hline
\end{tabular}

Table 2 Actions taken in GTBib and resulting statuses in WorldShare

\section{The ILL cycle as borrower}

Requests for documents reach the library through the forms that users have filled out or the links provided for this purpose by bibliographic databases or discovery tools. ILL staff review the data introduced and use the catalogues to identify potential lenders. For each of these libraries, the ILL system has a record including, among other data, the transmission method of the requests (email, fax, land mail, OpenURL, web services, etc.) and the address, URL or WSDL associated with that method. The connection data, user and password are also stored. A final requirement is that the library code assigned in the library directory must match the OCLC symbol in order for it to be assigned as a lender.

Thus, when the ILL staff choose a library belonging to the OCLC network, the system has already determined that the request should be sent using web services with WSDL WorldCatResourceSharing_v1_6.wsdl and connection data retrieved. The request is send consuming the createRequest web service and assigning the type PRODUCE, which creates and sends it to the supplier through the OCLC platform.

A current limitation of this process is that GTBib only assigns one supplier in each procedure. However, if the generic OCLC code is being used in the record library, the web service uses the type REVIEW_SAVE, which creates the request without sending it to the supplier, so ILL staff can later connect to the WorldShare interface to assign one or more suppliers.

This process is completely automatic and transparent. If the connection has been performed correctly, the system retrieves the OCLC identifier assigned to the request. This identifier is stored in GTBib as a supplier reference in the transaction record, so it can be used to perform further actions on this procedure.

\section{The ILL cycle as lender}

While librarians are using the ILL program, it periodically checks the WorldShare system for requests with PENDING status. When a borrower sends a request, this is reflected with a red circle in the options bar of the application. It is thus not necessary to keep accessing the OCLC interface and the information is received almost instantaneously.

\section{(2) Contacts | Request manager | Search | Billing | Reports | Tools | Logout}

Figure 3. Options bar

This article is (c) Emerald Group Publishing and permission has been granted for this version to appear here http://diposit.ub.edu . Emerald does not grant permission for this article to be further copied/distributed or hosted elsewhere without the express permission from Emerald Group Publishing Limited 
By clicking on the red circle, the librarian sees the request data grouped in different tabs (bibliographic data, administrative charging data, shipping data, etc.) and is offered the possibility of incorporating them in the system for processing. At this step the library's data can be entered in the library directory. During the process of incorporation, the identifier of the request received is stored in the user reference field, and as in the previous point this will be the reference for the system to make future queries or future actions in the WorldShare system. After the item request was created, the system displays a text box to allow the librarian to change the status to IN_PROCESS.

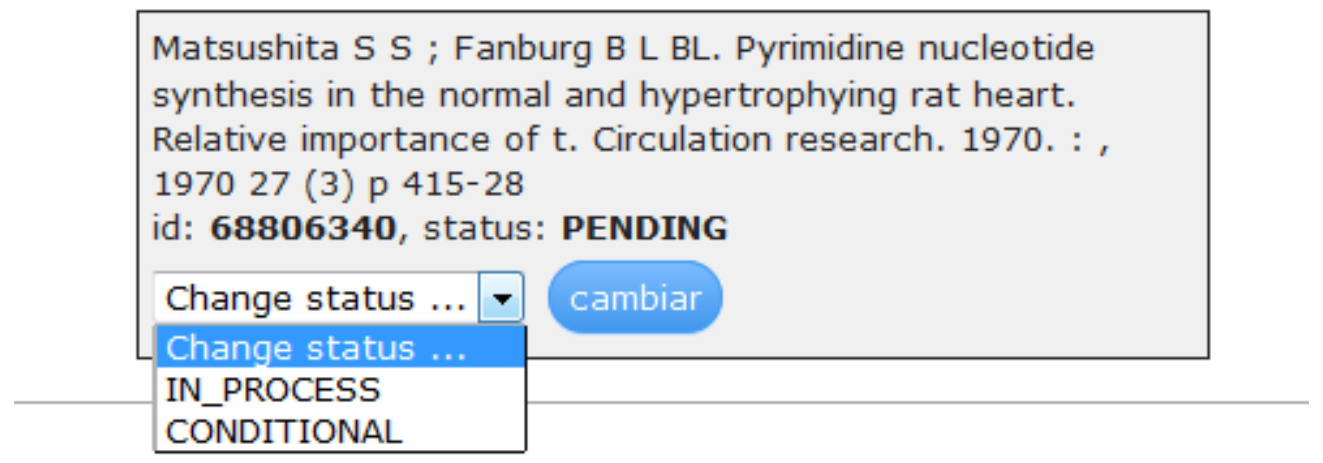

Figure 4. Change status to IN_PROCESS/CONDITIONAL

From now on three options are proposed:

- Fill the request: The system records the data and displays a text box to change the status to SHIPPED.

- Give a negative response: The system records the data and displays a text box to change the status to UNFILLED. In this case a dropdown is also displayed to allow users to choose the reason why the request could not be processed. This information is controlled by the WSDL, with the options shown in Figure 5.

- Give a conditional response that the request is left pending confirmation of the required conditions.

This article is (c) Emerald Group Publishing and permission has been granted for this version to appear here http://diposit.ub.edu . Emerald does not grant permission for this article to be further copied/distributed or hosted elsewhere without the express permission from Emerald Group Publishing Limited 


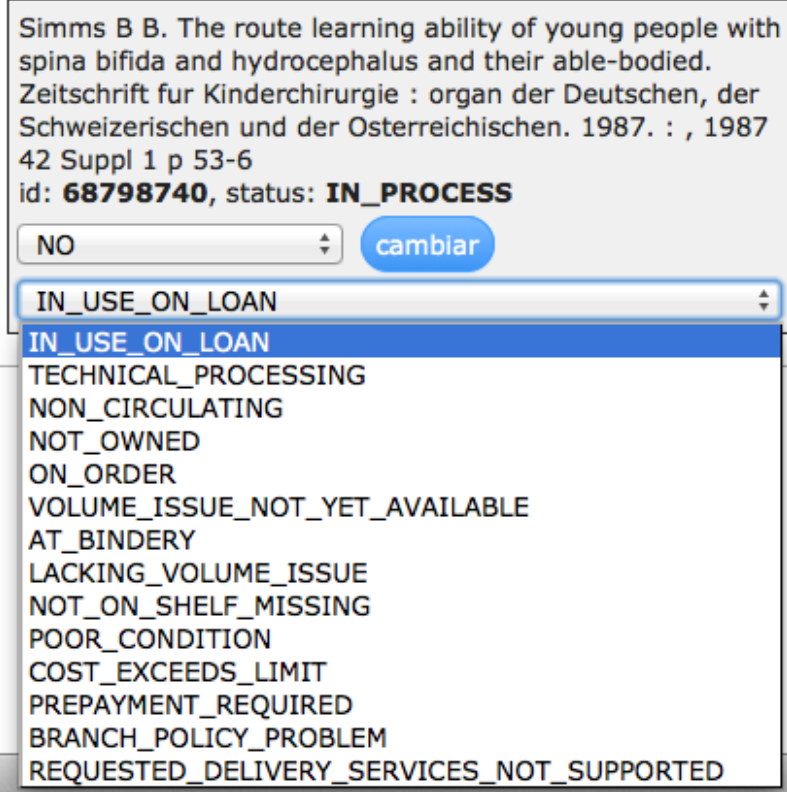

Figure 5 Options of negative response

\section{Using autonomous agents}

Regardless of the workflows described above, one of the advantages of integration is the use of agents that periodically run checks and maintain the integrity of the system unattended.

GTBib currently has two agents:

- Checking for arrival of new requests to the ILL service.

- Checking for changes of status of the requests being processed.

These agents typically run in scheduled tasks so it is not even necessary for the ILL staff to be connected. The frequency with which each agent runs can be configured independently so, for example, the task of checking the integrity of request statuses can be scheduled daily, whereas checking for daily arrival of new requests can be scheduled every $\mathrm{X}$ minutes.

In general, the agents perform the task assigned and if any action is required they send an email to the ILL staff. In some cases, the agent may make the necessary adjustments in the GTBib application automatically if no intervention is required. For example, when a document has been sent to a borrower and this library confirms receipt, the agent detects this change in the WorldShare status and automatically reflects it in the GTBib request record. In this case it seems unnecessary to send an email to the ILL staff but this information can be stored and submitted in a daily report.

If at any time a serious inconsistency is detected, the ILL staff are notified automatically by email. For example, this would happen if a request is detected in our system as pending management, whereas in WorldShare it appears as sent. Such problems may occur when the statuses of the requests are changed manually outside the usual workflow. In this case human intervention is necessary to determine the real status of the request and modify the system in which it is wrong.

This article is (c) Emerald Group Publishing and permission has been granted for this version to appear here http://diposit.ub.edu . Emerald does not grant permission for this article to be further copied/distributed or hosted elsewhere without the express permission from Emerald Group Publishing Limited 


\section{Conclusions and future directions}

The incorporation of university library collections in the OCLC WorldCat catalog is leading to a great increase in visibility for the participants and therefore an increase in their role as suppliers, especially of materials with linguistic, cultural or regional features that make them more likely to be held in specific libraries.

With regard to obtaining documents, though they can be requested directly from American libraries, the experience of libraries ${ }^{1}$ indicates that better responses are obtained if they are requested through the WorldShare Interlibrary Loan/WorldCat Resource Sharing platforms.

As $90 \%$ of Spanish university libraries have automated management of ILL using GTBib-SOD, using both platforms for the relations between Spanish and American libraries involves a duplication of tasks with a resulting increase in management time. An automatic interconnection between the two systems avoids this duplication, simplifying management and reducing time. Furthermore, agents that periodically check the matching of the request statuses in both systems allow errors to be corrected and increase the efficiency of the transactions.

This same type of interconnection is now being applied to other programs. At the University of Barcelona, for example, administrative data on the requests are synchronized using web services with the SAP central accounting system that centralizes the university's administrative management and billing. As a future proposal, we expect that this type of interconnection may also be the basis for linking with other ILL applications such as the Italian NILDE network.

\section{References}

Duke, J. (2013), "New WorldShare ILL Service Now Available”, Advanced technology libraries, Vol. 4, p. 2, available at: http://site.ebrary.com/pub/atl/docDetail.action?docID=10740395\&page=2.

Eberle, M. (2000), "Current Awareness Using PubMed”, Internet Reference Services Quarterly, Vol. 5 No. 2, pp. 21-29, doi:10.1300/J136v05n02_04.

Grupo de trabajo de préstamo Interbibliotecario de REBIUN. (2013), Manual de procedimiento de préstamo interbibliotecario, (REBIUN. Red de Bibliotecas Universitarias,Ed.), 3 revisón., available at: http://www.rebiun.org/documentos/Documents/PRÉSTAMO

INTERB/Manual_Prestamo_Interbibliotecario_revision_noviembre_2013.pdf.

Henzel, J., Hutchinson, B.S. and Thwaits, A. (2006), "Using web services to promote library-extension collaboration", Library Hi Tech, Vol. 24 No. 1, pp. 126-141, doi:10.1108/07378830610652158.

Interlibrary Loan Committee, R. and U.S.A. (RUSA). (2008), "Interlibrary Loan Code for the United States", American Library Association, available at: http://www.ala.org/rusa/resources/guidelines/interlibrary (accessed 24 January 2014).

International Association of Scientific Technical \& Medical Publishers. (2011), "STM Statement on Document Delivery", available at: http://www.stm-assoc.org/industry-news/stm-statement-ondocument-delivery.

\footnotetext{
${ }^{1}$ This information was obtained from a discussion thread on the SOD-L mailing list.
}

This article is (c) Emerald Group Publishing and permission has been granted for this version to appear here http://diposit.ub.edu . Emerald does not grant permission for this article to be further copied/distributed or hosted elsewhere without the express permission from Emerald Group Publishing Limited 
International Coalition of Library Consortia. (2011), "ICOLC Response to the International Association of Scientific Technical and Medical (STM)", available at: http://icolc.net/content/icolc-responseinternational-association-scientific-technical-and-medical-stm-statement.

International Federation of Library Associations and Institutions. (2001), "International Lending and Document Delivery: Principles and Guidelines for Procedure", available at: http://archive.ifla.org/VI/2/p3/ildd.htm (accessed 24 January 2014).

International Federation of Library Associations and Institutions. (2009), "International Resource Sharing and Document Delivery: Principles and Guidelines for Procedure", available at: http://www.ifla.org/en/publications/international-resource-sharing-and-document-delivery-principlesand-guidelines-for-proc (accessed 8 September 2012).

International Organization for Standardization. (1997a), "ISO 10160:1997 - Information and documentation -Open Systems Interconnection -- Interlibrary Loan Application Service Definition", available at: http://www.iso.org/iso/catalogue_detail?csnumber=22247 (accessed 12 September 2012).

International Organization for Standardization. (1997b), "ISO 10161-2:1997 - Information and documentation -- Open Systems Interconnection -- Interlibrary Loan Application Protocol Specification -- Part 2: Protocol implementation conformance statement (PICS) proforma", available at: http://www.iso.org/iso/home/store/catalogue_tc/catalogue_detail.htm?csnumber=21389 (accessed 12 September 2012).

Ishikawa, F., Tahara, Y., Yoshioka, N. and Honiden, S. (2005), “A framework for synthesis of web services and mobile agents", International Journal of Pervasive Computing and Communications, Vol. 1 No. 3, pp. 227-245, doi:10.1108/17427370580000128.

Jackson, M. (2005), "When a good standard development process fails", Interlending \& Document Supply, Emerald Group Publishing Limited, Vol. 33 No. 1, pp. 53-55, doi:10.1108/02641610510699983.

Mangiaracina, S., Zaetta, M., Matteis, D. De, Tugnoli, A., Beghelli, E. and Tenaglia, G. (2008), "NILDE: developing a new generation tool for document delivery in Italy", Interlending \& Document Supply, Vol. 36 No. 3, pp. 167-177, doi:10.1108/02641610810897908.

Murphy, B. (2011), "Spanish consortium BUCLE implements WorldCat Local”, null, available at: http://www.oclc.org/en-US/news/releases/2011/201122.html (accessed 22 October 2013).

National Information Standards Organization. (2012), ANSI/NISO Z39.83-1-2012, NISO Circulation Interchange Part 1: Protocol (NCIP), version 2.02, p. 106, available at: http://www.niso.org/apps/group_public/project/details.php?project_id=103 (accessed 3 December 2012).

Needleman, M., Bodfish, J., O’Brien, T., Rush, J.E. and Stevens, P. (2001), “The NISO circulation interchange protocol (NCIP) - an XML based standard", Library Hi Tech, Vol. 19 No. 3, pp. 223-230, doi:10.1108/07378830110405526.

Pitcher, K., Bowersox, T., Oberlander, C. and Sullivan, M. (2010), "Point-of-Need Collection Development: The Getting It System Toolkit (GIST) and a New System for Acquisitions and Interlibrary Loan

This article is (c) Emerald Group Publishing and permission has been granted for this version to appear here http://diposit.ub.edu . Emerald does not grant permission for this article to be further copied/distributed or hosted elsewhere without the express permission from Emerald Group Publishing Limited 
This article is a post-print version of Josep-Manuel Rodríguez-Gairín Marta Somoza-Fernández , (2014),"Web services to link interlibrary software with OCLC WorldShare", Library Hi Tech, Vol. 32 Iss 3 pp. 483 - 494

http://dx.doi.org/10.1108/LHT-12-2013-0158

Integrated Workflow and Collection Development", Collection Management, Vol. 35 No. 3, pp. 222 236, doi:10.1080/01462679.2010.486977.

Rodríguez-Gairín, J.-M. (2012), “20 años de automatización de préstamo interbibliotecario en España (19922012)", El profesional de la información, Vol. 21 No. 6, pp. 557-566, doi:10.3145/epi.2012.nov.02.

Rykowski, J. (2007), "Virtual Web Services”, Journal of Digital Information, Vol. 8 No. 3, available at: http://journals.tdl.org/jodi/index.php/jodi/article/view/234 (accessed 11 November 2013).

Schall, D., Aiello, M. and Dustdar, S. (2006), "Web services on embedded devices", International Journal of Web Information Systems, Vol. 2 No. 1, pp. 45-50, doi:10.1108/17440080680000100.

Vizine-Goetz, D., Houghton, A. and Childress, E. (2006), "Web services for controlled vocabularies", Bulletin of the American Society for Information Science and Technology, Vol. 32 No. 5, pp. 9-12, doi:10.1002/bult.2006.1720320505.

Wusteman, J. (2006), "Realising the potential of web services", OCLC Systems \& Services, Vol. 22 No. 1, pp. 5-9, doi:10.1108/10650750610640739.

Zarei, H. and Abazari, Z. (2011), "A study of web-based services offered by Asian national libraries", The Electronic Library, Vol. 29 No. 6, pp. 841-850, doi:10.1108/02640471111188051.

\section{About the authors}

Josep-Manuel Rodríguez-Gairín has been a tenured Lecturer at the Faculty of Library and Information Science of the University of Barcelona (UB) since 1998. He teaches courses related to information technology and the Internet. He has a Degree in Medicine from the UB and was responsible for the Teledocumentation Service between 1987 and 1991. From 1991 to 1999 hewas Head of the Electronic Information Support Unit in the Technical Services of the Universitat Politècnica de Catalunya (UPC), which included teledocumentation services, the CDROM network and the document access and ILL service. During this time he developed the GTBib-SOD program for managing the ILL service. He has developed the technological infrastructure of projects such as the EXIT directory of experts in information processing (www.directorioexit.info), IraLIS (International Registry of Authors-Links to Identify Scientists, www.iralis.org) and Dulcinea (copyrights and conditions of self-archiving of Spanish scientific journals, www.accesoabierto.net/dulcinea), among others: http://bd.ub.edu/pub/rzgairin; http://www. directorioexit.info/ficha16; http://scholar.google.com/citations?user=El_9KHMAAAAJ. Josep-Manuel Rodríguez-Gairín is the corresponding author and can be contacted at: rodriguez.gairin@ub.edu

Dr Marta Somoza-Fernández has Degrees in Contemporary History (1989) and Cultural Anthropology (1995) and is a Doctor of Documentation (2009) from the University of Barcelona (UB). He was responsible for Teledocumentació Servei de l'Area de Ciències Health Service Library UB until 2002. Since 1999 he is a Professor at the Department of Library and Information UB. His research interests focus on document databases, information retrieval, bibliometric studies and user training: http://bd.ub.edu/pub/msomoza; www.directorioexit.info/ficha159; http://scholar.google.com/citations?user=9RbIq8QAAAAJ

This article is (c) Emerald Group Publishing and permission has been granted for this version to appear here http://diposit.ub.edu . Emerald does not grant permission for this article to be further copied/distributed or hosted elsewhere without the express permission from Emerald Group Publishing Limited 